\title{
Formation of In-Situ Dispersion Strengthening Particles in Cast FeCrAl Alloy
}

\author{
FENG Shuo ${ }^{1}$, HAN Wei ${ }^{2}$, LUO He-li ${ }^{1}$, Karin $\mathrm{G}^{3}$, LI Chang-hai ${ }^{3}$ \\ (1. High Temperature Material Research Institute, Central Iron and Steel Research Institute, Beijing 100081, China; \\ 2. Group (Iffice, China Iron and Steel Research Group. Beijing 100081. China; 3. Department of Materials \\ Science and Engineering, Chalmers University of Technology, Gothenburg SE-412 96, Sweden)
}

\begin{abstract}
In order to fabricate dispersion strengthened alloys strengthened by submicron-sized or nano-sized stable particles through casting routes, understanding of the formation process of dispersion strengthening particles in metal melt is of significance. Thus, nano $\mathrm{NiO}$ and $\mathrm{Ti(})_{2}$ particles were selected as reactant to form in-situ dispersion strengthening oxide particles in $\mathrm{Fe} 20 \mathrm{Cr} 5 \mathrm{Al}$ alloy. Nano $\mathrm{NiO}$ and $\mathrm{TiO})_{2}$ particle powder was separately dispersed into nano $\mathrm{Ni}$ powder first. The loose mixed nano powder was added in $\mathrm{Fe} 20 \mathrm{Cr} 5 \mathrm{Al}$ alloy melt when pouring the melt into mold. The study shows that nano $\mathrm{NiO}$ ) particles were not as effective as nano $\mathrm{Ti}()_{2}$ particles in forming dispersion strengthening $\mathrm{Al}_{2} \mathrm{O}_{3}$ particles. The final diameters of dispersion strengthening oxide particles arose from nano $\mathrm{TiO}_{2}$ particles were of submicron. The Brownian collision of particles had caused this coarsening.
\end{abstract}

Key words: in-situ particle; dispersion strengthening particle; formation; cast FeCrAl alloy

The mechanisms responsible for the formation of in-situ reinforcements have been widely studied in the development of particles reinforced metal matrix composites produced by casting routes ${ }^{1-2 j}$. In order to fabricate submicron or nano-sized particles strengthened composites or dispersion strengthened alloys through casting routes ${ }^{[3-5]}$, understanding of the formation mechanisms of dispersion strengthening fine particles in metal melt is of significance. In present work, nanosized oxides were selected as reactant to form disper sion strengthening particles in Fe $20 \mathrm{Cr} 5 \mathrm{Al}$ melt. The behaviors of these nano-sized oxides of great number density in steel melt were studied.

\section{Experimental}

The investigations of oxide dispersion strengthened alloys produced by powder metallurgy routes show that the oxides mass percent of $0.5 \%-1 \%$ and oxides size of about $30 \mathrm{~nm}$ are ideal parameters (the particles number density is of about $10^{211} \mathrm{~m}^{-3}$ ) to achieve the best mechanical properties combination $^{[6]}$. In present experiments, the average diame- ter of original particles is about $30 \mathrm{~nm}$ (measured by small angle scattering method) and the mass percent of the oxides powder added into testing alloys is about $0.5 \%$ and the chemical composition of the testing alloys are shown in Table 1 . NiO was selected as an unstable oxide and $\mathrm{Ti}()_{2}$ (rutile) was selected as a stable oxide (more stable than oxides of iron and chromium, but less stable than $\mathrm{Al}_{2} \mathrm{O}_{3}$ ). Because of the presence of $5 \% \mathrm{Al}$ (in mass percent) in the melt, these oxides should be reduced to $\mathrm{Al}_{2} \mathrm{O}_{3}$ after entering into melt. In this study, the following two issues are intended to be clarified: firstly, which oxide is more effective as the nuclei of forming nano-sized or ultrafine $\mathrm{Al}_{2} \mathrm{O}_{3}$ particles; secondly, whether the newly formed $\mathrm{Al}_{2} \mathrm{O}_{3}$ particles keep the same size of the nano reactant particles.

Because nano oxide particles are easily agglomerated, dispersion agent is needed. Nano-sized $\mathrm{Ni}$ powder was selected as the dispersion agent. Nano $\mathrm{Ni}$ powder and nano oxide powder were blended in acetone with ultrasonic stirring, and then the mixed nano powder was dried.

Foundation Item : ltem Sponsored by International (o-operation Project (20061415)

Biography: FENG Shuo(1985-), Male. Master; E-mail: fengshuol985a@yahoo. com. cn: Received Date: November 10 , 2008 
Table 1 Nominal chemical composition of the test alloy

\begin{tabular}{|c|c|c|c|c|c|c|}
\hline \multirow{2}{*}{ Alloy No. } & \multicolumn{3}{|c|}{ Base } & \multicolumn{2}{|c|}{ Oxide powder } & \multirow{2}{*}{$\begin{array}{l}\text { Dispersion agent } \\
\text { Nano carbonyl Ni }\end{array}$} \\
\hline & $\mathrm{Fe}$ & $\mathrm{Cr}$ & $\mathrm{Al}$ & Nano $\mathrm{NiO}$ & Nano $\mathrm{TiO}_{2}$ (rutile) & \\
\hline $1=$ & Balance & 20 & 5 & 0.5 & - & 1.5 \\
\hline $2=$ & Balance & 20 & 5 & - & 0.5 & 1.5 \\
\hline
\end{tabular}

The prepared loose mixed nano powder was charged into steel mold and the mold was set into vacuum chamber before vacuum induction melting. Base alloy was melt in a vacuum induction furnace using pure iron, pure chromium and pure aluminum. The melting point of base alloy is about $1500{ }^{\circ} \mathrm{C}$, and the pouring temperature was $1580{ }^{\circ} \mathrm{C}$. The alloy melt solidified in several seconds after pouring. Each steel ingot was in the mass of about $4 \mathrm{~kg}$.

Samples for metallographic observation and extraction of oxides were machined by electric discharge machining from the different ingot areas. The specimens for microstructure examination cut from the cast ingots were ground, polished and chemically etched with $10 \mathrm{~mL} \mathrm{HF}+10 \mathrm{~mL}, \mathrm{HNO}_{3}+80 \mathrm{~mL} \mathrm{H}_{2} \mathrm{O}$ solution. Hydrochloric acid solution $\left(\mathrm{HCl}: \mathrm{H}_{2} \mathrm{O}=1\right.$ : 4) was used to extract oxides in the testing alloys. SEM equipped with EDS system was used to reveal microstructure details and phase composition.

\section{Results and Discussion}

\section{1 Ni and Ti distribution at macroscopic scale}

Table 2 shows the average $\mathrm{Ni}$ and $\mathrm{Ti}$ content of the three different parts of the ingots [EDS (energy dispersive spectrometer) average composition analysis on surface at the magnification of 100]. Some powder was splashed and lost in the pouring process, so the amount of nano powder that entered into steel stream was less than that charged into the mold. Element $\mathrm{Ni}$ is uniformly distributed in both alloys samples. The uniformity of the Ti distribution (the indicator of the presence of $\mathrm{TiO}_{2}$ ) was poor at macroscopic scale. Some parts of the ingots had no Ti distribution. This was a shortcoming of the process.

Table 2 The $\mathrm{Ni}$ and $\mathrm{Ti}$ contents in three

\begin{tabular}{|c|c|c|c|}
\hline & differ & & cent, \\
\hline \multirow{2}{*}{ Area No. } & $1=$ alloy & \multicolumn{2}{|c|}{$2^{=}$alloy } \\
\hline & $\mathrm{Ni}$ & $\mathrm{Ni}$ & $\mathrm{Ti}$ \\
\hline 1 & 0.56 & 0.45 & 0.12 \\
\hline 2 & 0.62 & 0.70 & 0 \\
\hline 3 & 0.58 & 0.91 & 0.1 \\
\hline
\end{tabular}

\section{2 Oxide distribution at microscopic scale}

Fig. 1 shows the typical oxides found in $1^{\#}$ alloy samples. Cluster-like phases in Fig. 1 (a) are $\mathrm{Al}_{2} \mathrm{O}_{3}$. The tube-like phase in Fig. 1 (b) contains Al, O and $\mathrm{N}$ through the EDS analysis, but the exact identity is not clear. The fine particles of about $0.5 \mu \mathrm{m}$ in Fig. 1 (b) are $\mathrm{Al}_{2} \mathrm{O}_{3}$ granules, which was verified by shape and EDS chemical composition analysis of extraction residua as shown in Fig. 1 (c) and (d).

Fig. 2 (a) shows the dispersion strengthening oxides distribution in $2^{\#}$ alloy samples. EDS chemical composition analysis shows that $\mathrm{Ti}$ and $\mathrm{Ni}$ exist in this area. This suggests that those oxides are relative with the intentionally added nano $\mathrm{TiO}_{2}$ powder. The average diameter of the oxides is in the range of $0.1-0.3 \mu \mathrm{m}$, which is larger than the initial oxides diameter (about $30 \mathrm{~nm}$ ). Fig. 2 (b) shows the chemical composition of the extraction residua. It shows that $\mathrm{TiO}_{2}$ particles were partially reduced by $\mathrm{Al}$ in the steel melt.

Fig. 3 shows a casting defect surface of $2^{\#}$ alloy. Spherical particles of different sizes are found on the surface. Table 3 shows the chemical composition of two large spherical particles. The spherical particles are not pure oxide particles but the mixture of base alloy and oxides. This suggests that when nano powder agglomerate contacted with steel stream, steel melt infiltrated into the space between nano particles. This mechanism is in favor of the nano oxide particles entering into steel stream.

\section{3 Discussion}

According to the design in this study, when the mixed nano powder meets the high temperature molten steel stream, nano nickel particles will melt and be mixed into steel stream, and the nano oxide particles which dispersed in nano nickel powder will also disperse into steel stream. According to the Gibbs free energies of oxides formation, the following reactions will exist:

$$
\begin{aligned}
& (\mathrm{NiO})_{\mathrm{s}}+[\mathrm{Al}] \rightarrow[\mathrm{Ni}]+\left(\mathrm{Al}_{2} \mathrm{O}_{3}\right)_{\mathrm{s}} \\
& \left(\mathrm{TiO}_{2}\right)_{\mathrm{s}}+[\mathrm{Al}] \rightarrow[\mathrm{Ti}]+\left(\mathrm{Al}_{2} \mathrm{O}_{3}\right)_{\mathrm{s}}
\end{aligned}
$$



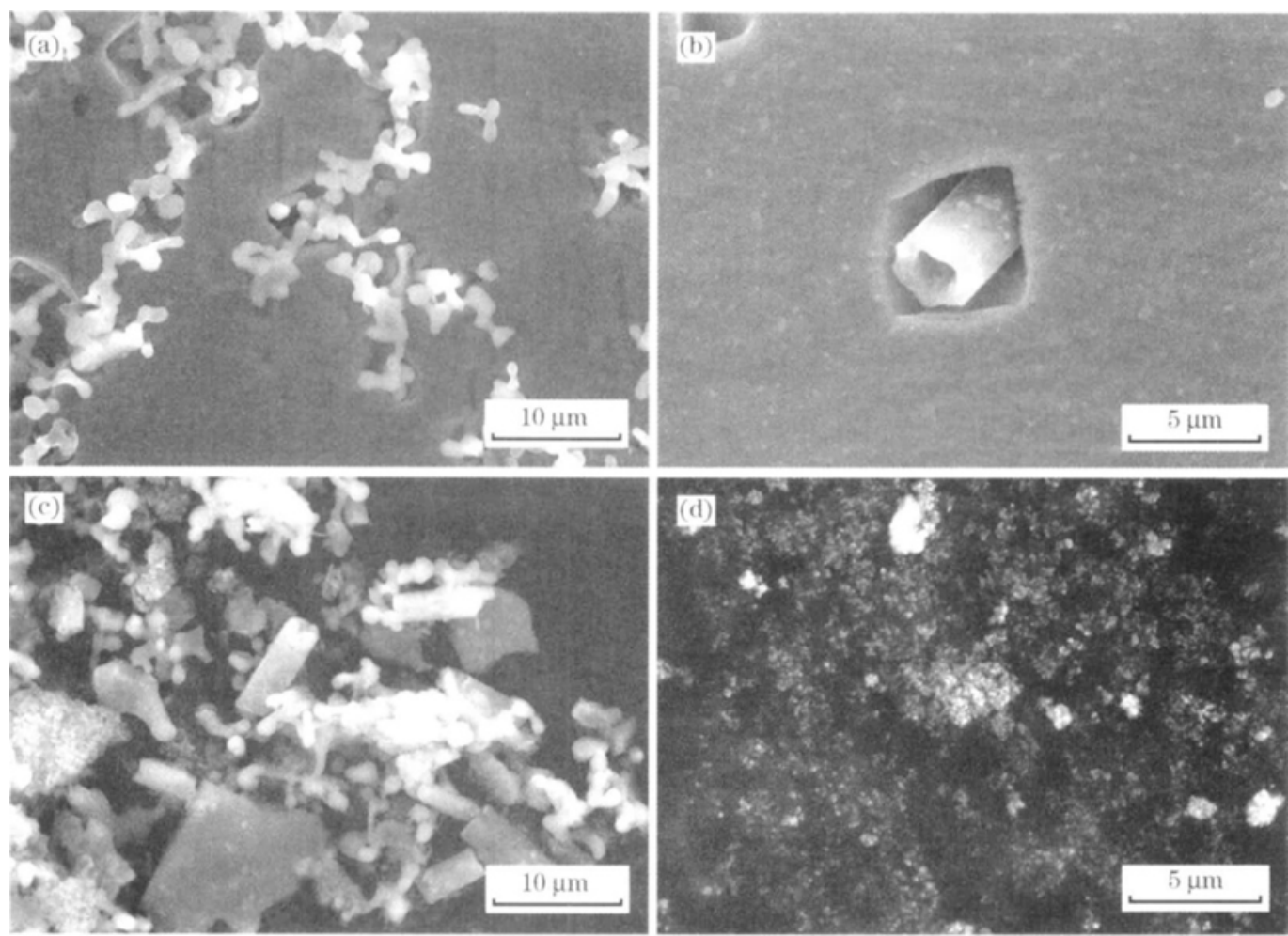

(a) Cluster-like $\mathrm{Al}_{2} \mathrm{O}_{3}$ found in 1 = alloy;

(b) Tube-like phase and line $\mathrm{Al}_{2} \mathrm{O}_{3}$ granules found in $1=$ alloy;

(c) Extracted residua containing cluster-like and tube-like phases of 1 " alloy;

(d) Extracted residua containing fine $\mathrm{Al}_{2}\left(\mathrm{O}_{3}\right.$ granules of $1 \neq$ alloy.

Fig. 1 Oxides found in 1 alloy
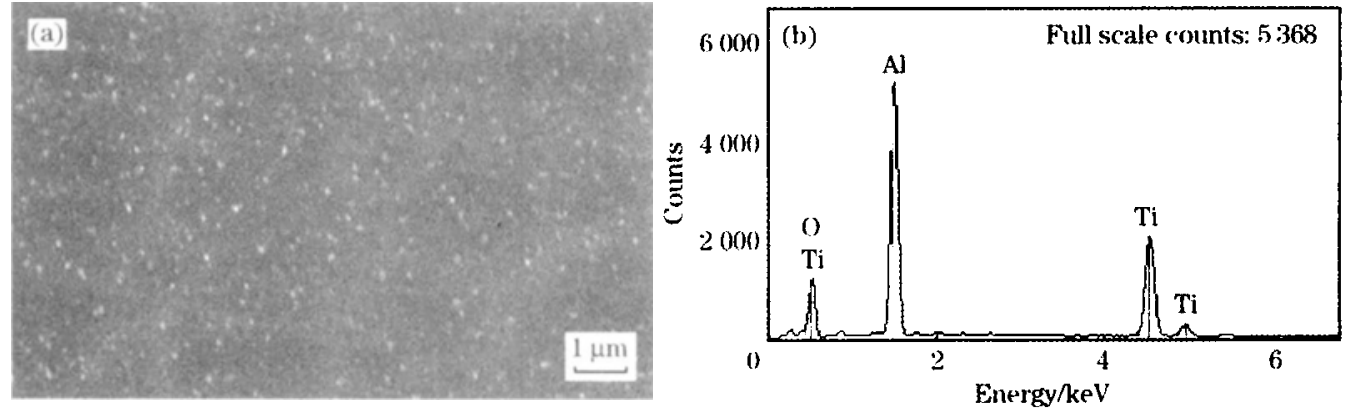

(a) Distribution of oxide particles in $2=$ alloy;

(b) Chemical composition of extracted residua of $2=$ alloy.

Fig. 2 The oxides distribution and chemical composition of the oxides found in 2 alloy

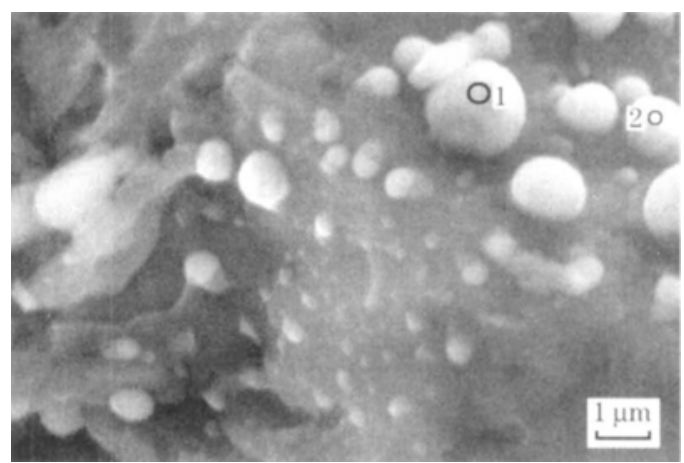

Fig. 3 One casting defect surface of $2=$ alloy with spherical particles on it
As shown in Fig. 1 (b) and Fig. 2 (a), nano $\mathrm{NiO}$ particles were not as effective as $\mathrm{TiO}_{2}$ to form dispersed $\mathrm{Al}_{2} \mathrm{O}_{3}$ granules. In contrast, the $\mathrm{NiO}$ powder caused the appearance of micron-sized cluster-like and tube-like $\mathrm{Al}_{2} \mathrm{O}_{3}$ in $\mathrm{l}^{\text {\# }}$ alloy and the size of the fine $\mathrm{Al}_{2}, \mathrm{O}_{3}$ granules arose from $\mathrm{NiO}$ ) was larger than that

Table 3 Composition of spherical particles in Fig. 3 (atomic percent, \%)

\begin{tabular}{ccccccc}
\hline Element & $(3$ & $\mathrm{Al}$ & $\mathrm{Ti}$ & $\mathrm{Cr}$ & $\mathrm{Fe}$ & $\mathrm{Ni}$ \\
\hline Particle 1 & 7.38 & 12.50 & 2.82 & 16.60 & 58.64 & 2.06 \\
Particle 2 & 12.83 & 15.38 & 2.88 & 14.42 & 52.54 & 1.95 \\
\hline
\end{tabular}


arose from $\mathrm{TiO}_{2}$. Because $\mathrm{NiO}$ is less stable than $\mathrm{TiO}_{2}$, reaction (1) may consist of the following two reactions:

$$
\begin{aligned}
& (\mathrm{NiO}) \mathrm{s} \rightarrow[\mathrm{Ni}]+[\mathrm{O}] \\
& {[\mathrm{O}]+[\mathrm{Al}] \rightarrow\left(\mathrm{Al}_{2} \mathrm{O}_{3}\right) \mathrm{s}}
\end{aligned}
$$

Namely, NiO decomposed first. Oxygen atoms in the melt quickly diffused toward the few existing $\mathrm{Al}_{2} \mathrm{O}_{3}$ nuclei. $\mathrm{Al}_{2} \mathrm{O}_{3}$ nuclei can grow to micron-sized in seconds by this "diffusion-growth" mechanism" ${ }^{[7]}$. This can explain the appearance of micron-sized $\mathrm{Al}_{2} \mathrm{O}_{3}$ in $1^{\#}$ alloy.

Stable oxide $\mathrm{TiO}_{2}$ did not decompose in high temperature melt. They dispersed into melt as solid nuclei and oxygen source for the formation of more stable $\mathrm{Al}_{2} \mathrm{O}_{3}$ particles. Aluminum atoms in the melt diffused toward the $\mathrm{TiO}_{2}$ particles and reduced the $\mathrm{TiO}_{2}$ into $\mathrm{Al}_{2} \mathrm{O}_{3}$ gradually. The reduction reaction (solid-liquid reaction) rate was limited and the reaction time (from start pouring to solidification finish) was limited, so the $\mathrm{TiO}_{2}$ particles were only partially reduced.

Then the second issue arises: why the final dispersion strengthening particles (partially reduced $\mathrm{TiO}_{2}$ particles) size in $2=$ alloy is still larger than the initial particles size? It is well known that the finer the oxides are, the better the effect of dispersion strengthening. The growth of oxide particles should be prevented or controlled.

For the average diameter of oxides particles is below micron, the behavior of these particles should be governed by Brownian motion. Brownian motion causes fine particles to spread and causes particles growth by collision between particles. The first effect is in favor of achieving dispersion strengthening and the second effect hinders the realization of dispersion strengthening through casting route.

The average square displacement $\bar{x}^{2}$ of the fine particles can be calculated by the following equation $^{[8]}$ :

$$
\bar{x}^{2}=\frac{2 k T}{\alpha} t=2 D_{\mathrm{p}} t
$$

where, $k$ is Boltzmann constant $k=1.38 \times 10^{-23} \mathrm{~J} \cdot$ $\mathrm{K}^{-1} ; T$ is thermo-dynamical temperature, $\mathrm{K} ; t$ is time, $\mathrm{s} ; \alpha$ is resistance coefficient caused by viscosity, $\alpha=6 \pi r \eta ; r$ is the average radius of particles; $\eta$ is the viscosity coefficient of the melt, $\mathrm{N} \cdot \mathrm{s} / \mathrm{m}^{2}$; and $D_{\mathrm{p}}$ is the "diffusion" coefficient of the particles, $D_{\mathrm{p}}=$ $k T / \alpha$.

In this experiment, the average square displacement can be estimated as follows: assume the tem- perature $T$ is $1853 \mathrm{~K}, r$ is $30 \mathrm{~nm}$ and $\eta$ equals to $6.1 \times$ $10^{-3} \mathrm{~N} \cdot \mathrm{s} / \mathrm{m}^{2}$, then the particle average square displacement in one second $\bar{x}^{2}=1.5 \times 10^{-11} \mathrm{~m}^{2}\left(\sqrt{\mathrm{x}^{2}}=\right.$ $\left.3.87 \times 10^{-6} \mathrm{~m}\right)$ is achieved. This means that Brownian motion assure the uniformity of particle distribution in the range of several micron as seen in Fig. 1 (b) and Fig. 2 (a).

The particles number density $N(t)$ varies with time can be calculated by the following equation proposed by Smoluchowski ${ }^{[9]}$ :

$$
N(t)=\frac{N(0)}{1+8 \pi D_{\mathrm{p}} r N(0) t}
$$

The relationship between particles number density $N(t)$ and the particles average diameter $d(t)$ can be calculated by the following equation:

$$
N(t)=\frac{6}{\pi} \frac{\rho_{1}}{\rho_{2}} \frac{f_{\mathrm{w}}}{d^{3}(t)}
$$

where, $\rho_{1}$ is the melt density; $\rho_{2}$ is the oxide density; and $f_{\mathrm{w}}$ is the mass fraction of the oxides in the melt.

In present experiment, $N(0)$ is about $10^{20} \mathrm{~m}^{-3}$. Assume the same $D_{\mathrm{p}}$ and $r$ as before, $\rho_{1} / \rho_{\mathrm{r}}=2, f_{\mathrm{w}}=$ 0.002 and the $N(t)$ and $d(t)$ curves are shown in Fig. 4.

Fig. 4 shows that because of the presence of Brownian collision, a large number of nano oxide particles in steel melt will grow to $300 \mathrm{~nm}$ in $1 \mathrm{~s}$ from the original diameter of $30 \mathrm{~nm}$. Considering the temperature of melt dropped quickly and the viscosity of the melt rose after pouring, the practical time might be a little longer. This explains why the final diameters of dispersion strengthening oxide particles in $2^{\#}$ alloy were in the range of $100-300 \mathrm{~nm}$. Some measures, such as increasing melt viscosity, introducing ultrasonic stirring into the melt ${ }^{[4]}$ and so on, should be adopted to reduce or counteract the effect of

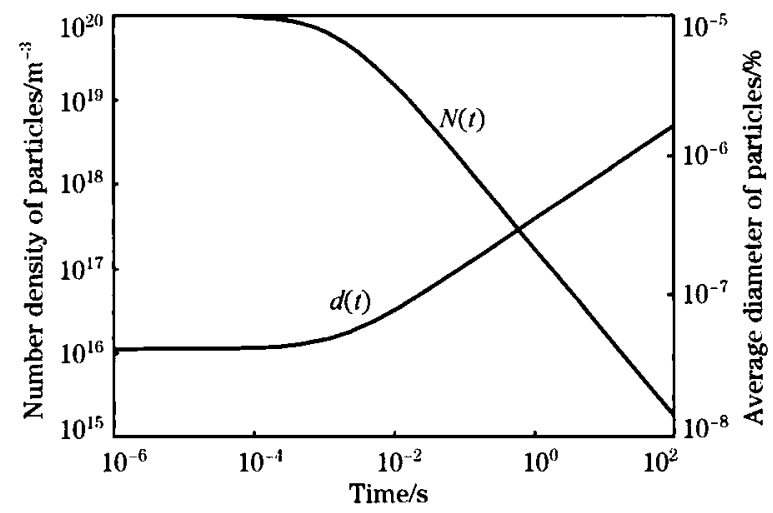

Fig. 4 Variation of $N(t)$ and $d(t)$ with time caused by Brownian collision 
Brownian collision.

\section{Conclusions}

1) Nano $\mathrm{NiO}$ decomposed first after entering steel melt. The oxygen atoms diffused to a few $\mathrm{Al}_{2} \mathrm{O}_{3}$ nuclei and the process promoted the appearance of micron-sized $\mathrm{Al}_{2} \mathrm{O}_{3}$. A certain number of $\mathrm{Al}_{2} \mathrm{O}_{3}$ granules of about $0.5 \mu \mathrm{m}$ were formed in the melt. Nano $\mathrm{NiO}$ (unstable oxide) particles were not effective nuclei of forming dispersion strengthening $\mathrm{Al}_{2} \mathrm{O}_{3}$ granules.

2) Nano $\mathrm{TiO}_{2}$ particles dispersed into melt were partially reduced by aluminum. Nano $\mathrm{TiO}_{2}$ particles were more effective nuclei of forming dispersed $\mathrm{Al}_{2} \mathrm{O}_{3}$ granules, compared with nano $\mathrm{NiO}$ particles. But the average diameter of final oxides was still larger than the initial particle diameter. The newly formed oxides had coarsened.

3) Brownian collision caused the newly formed nano oxide particles to grow to submicron-sized in seconds. Measures such as ultrasonic stirring are needed to keep the nano oxides particles separate.

\section{References:}

[1] Tjong S C, Ma Z Y. Microstructural and Mechanical Characteristics of in Situ Metal Matrix Composites [J]. Mater Sci Eng, 2000, 29: 49.

[2] Dolata-Grosz A. Sleziona J. Formanek B. Structure and Properties of Aluminium Cast Composites Strengthened by Dispersion Phases [J]. J Mater Proc Tech, 2006, 175: 192.

[3] Hasegawa M. Osawa M. Oxide Dispersion Strengthened Nickel-Base Heat Resistant Alloys by Means of the Spray Dispersion Method [J]. Metall Trans, 1985, 16A: 1043.

[4] YANG Yong. LAN Jie, LI Xiao-chun. Study on Bulk Aluminum Matrix Nanocomposite Fabricated by Ultrasonic Dispersion of Nano-Sized SiC Particles in Molten Aluminum Alloy [J]. Mater Sci Eng, 2004, 380A: 378.

[5] Hassan S F, Gupta M. Development of Nano- $\mathrm{Y}_{2} \mathrm{O}_{3}$ Containing Magnesium Nanocomposites Using Solidification Processing [J]. J Alloys and Compounds, 2007, 429: 176.

[6] Donachie M J. Donachie S J. Superalloys: A Technical Guide [M]. 2nd ed. Materials Park: ASM International, 2002.

[7] ZHANG Bang-wen, LI Bao-wei, HE You-duo. Growth Kinet ies of Single Inclusion in Molten Metal [J]. J Iron Steel Research. 2005, 17(6): 19 (in (hinese).

[8] WANG Zhi-cheng. Thermodynamics and Statistical Physics [M]. Beijing: Higher Education Press. 2003 (in Chinese).

[9] Myers D. Surfaces, Interfaces and Colloids-Principles and Applications [M]. New York: Wiley-VCH, 1999. 